\title{
Assessing Reliability and Validity of the Persian version of Infertility Stigma Scale (ISS) in Infertile Women
}

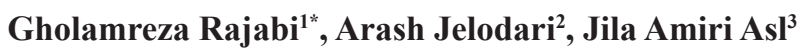

1. Department of Counseling and Educational Psychology, Ahvaz University of Shahid Chamran, Ahvaz, Iran

2. MSc Student, Ahvaz University of Shahid Chamran, Ahvaz, Iran

3. MSc, Ahvaz University of Shahid Chamran, Ahvaz, Iran

\begin{tabular}{lc}
\hline \multicolumn{1}{c}{ Article Info } \\
\hline & \\
Received: & $2016 / 10 / 5$ \\
Accepted: & $2017 / 04 / 29$ \\
Published Online & $2017 / 07 / 17$
\end{tabular}

DOI:

Original Article

Use your device to scan and read the article online

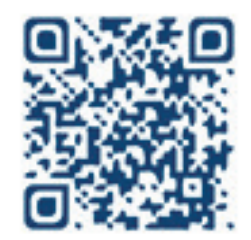

\section{Abstract}

Background: Stigma is accounted important structure in mental health areas, and one of the most important is infertility disorder consequences. The aim of the current research was to evaluate reliability and validity of the Persian version of Infertility Stigma Scale among infertile women.

Methods: The current research was psychometric of methodological type. One hundred and sixty six infertile women were selected using purposive sampling method and via interviews from Jahad Daneshgahi Infertility Treatment Center of Khuzestan. They filled out the Infertility Stigma, Rosenberg Self-esteem, General self-efficacy Beliefs and Self-Criticism scales. Data were analyzed using confirmatory factor analysis and fitness indices and by Amos and SPSS-21 software.

Results: In the exploratory factor analysis using Varimax rotation in the Persian of the Infertility Stigma Scale four factors extracted: Personal devaluation, social withdraw, general stigma, and family stigma that accounted for $62.49 \%$ of the variance. Also, Cronbach's $\alpha$ coefficients (internal consistency) were satisfactory for the whole scale and in extracted four factors, test-retest reliability coefficient of the scale with two-week interval was 0.58 and its divergent validity coefficient with Rosenberg Self-esteem and General Self-efficacy Scales and its convergent validity with Self-criticism Scale were statistically significant $(\mathrm{p}<0.001)$.

Conclusions: Given the appropriate validity and reliability of the scale, it can be used for research activities among this type of population and in infertility research and therapeutic center.

Keywords: Infertility; Validity and Reliability; Stigma; Women
Corresponding Information
Gholamreza Rajabi, Department of Counseling and Educational Psychology, Ahvaz University of Shahid Chamran, Ahvaz, Iran. Email: rajabireza@scu.ac.ir

Copyright $($ C 2017, Sci J Hamadan Nurs Midwifery Fac. This is an open-access article distributed under the terms of the Creative Commons Attribution-noncommercial 4.0 International License which permits copy and redistribute the material just in noncommercial usages, provided the original work is properly cited.

How to Cite This Article:

Rajabi G, Jelodari A, Amiri Asl J. Assessing Reliability and Validity of the Persian version of Infertility Stigma Scale (ISS) in Infertile Women. Sci J Hamadan Nurs Midwifery Fac. 2017; 25 (4): 104-113 


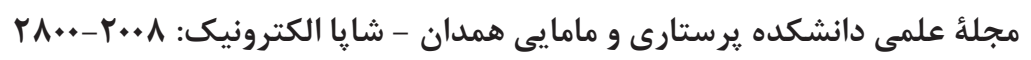

مقاله يزوهشى مامايى همدان

ارزيابى يايايى و روايى نسخة فارسى مقياس انتَ نابارورى (ISS) در زنان نابارور

\section{غلامرضا رجبى "'، آرش جلودارى'، زيلا اميرى اصل"}

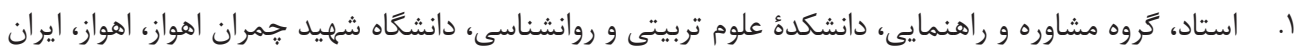

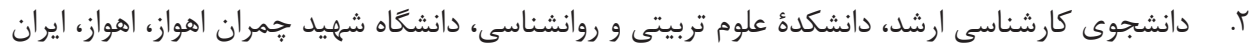

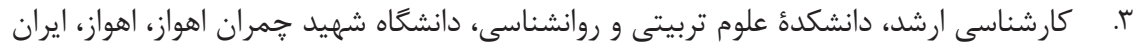

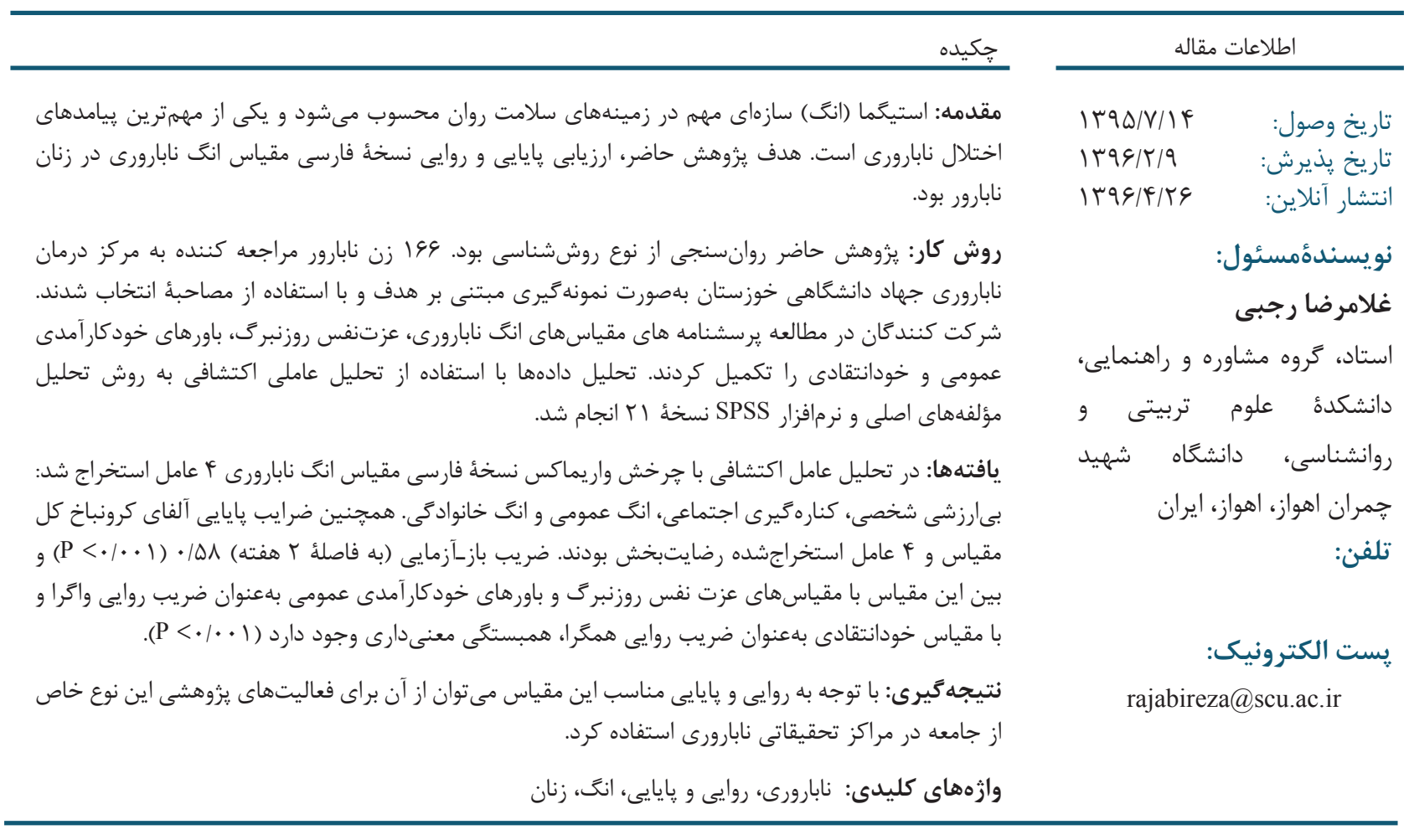

مقلدمه

وجود دارد [V]. برخى كاهش زيادى را در ارتباطاتشان تجربه

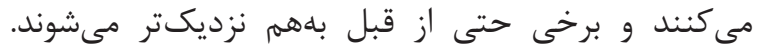

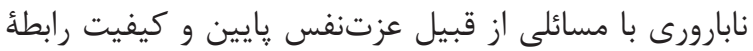

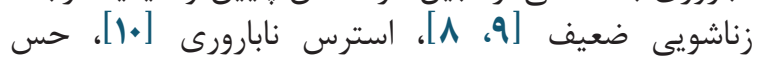

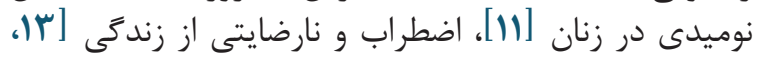

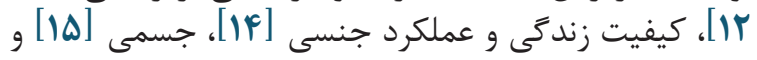
غيره در ارتباط است.

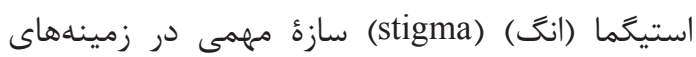

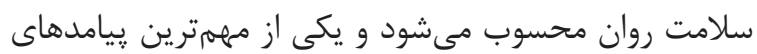

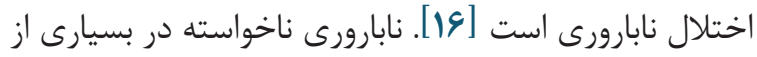

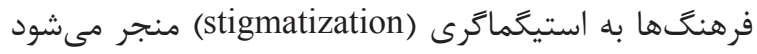

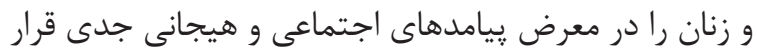

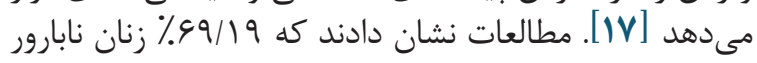

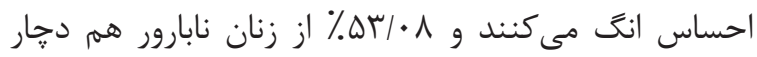

Practice committee of the American Society for Reproductive Medicine

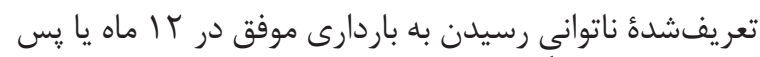
از آميزش مناسبَ محافظت نشده يا اهداى درئ درمانى اسيرم

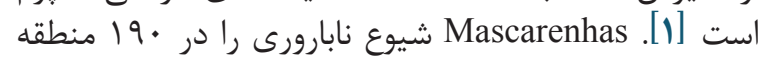

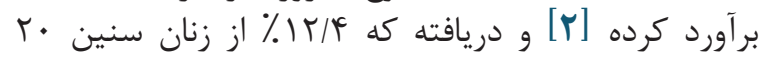

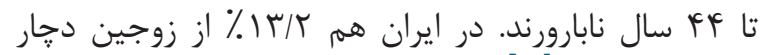

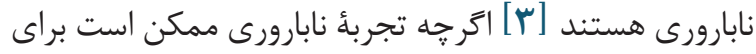

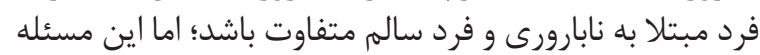

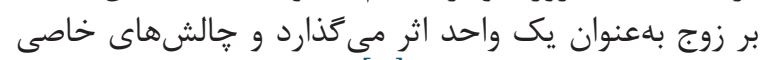

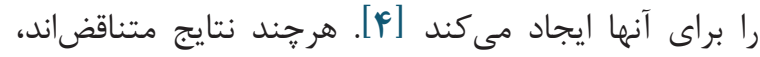

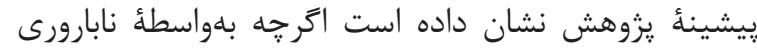

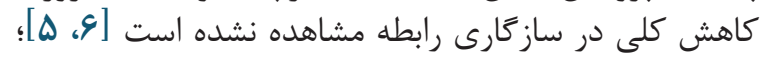

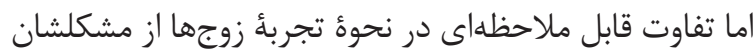


بهعنوان احساس فقدان عزتنفس و منزلت، ترس، شرم، كَناه

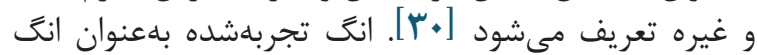

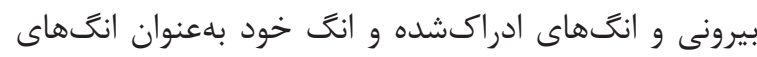

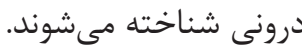

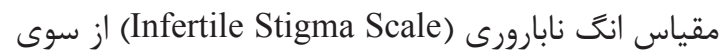
FU

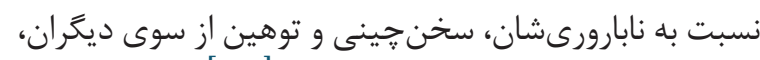

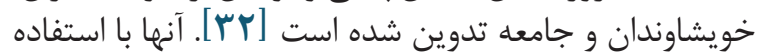
از تحليل عامل اكتشافى روى مقياس انَّ نابارورى (ISS)

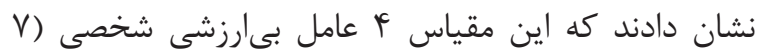

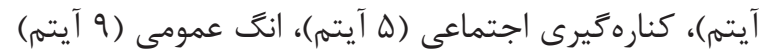

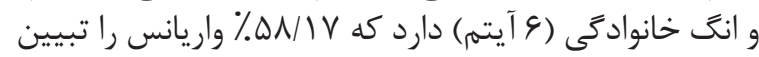

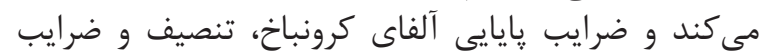

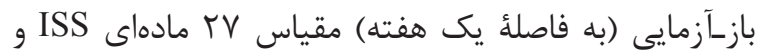

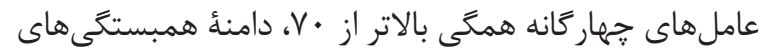

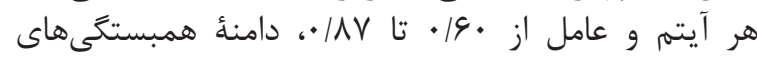

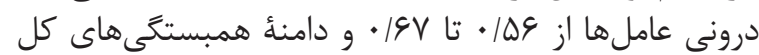

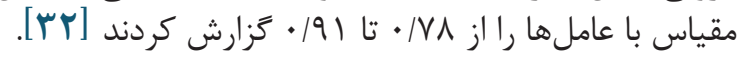

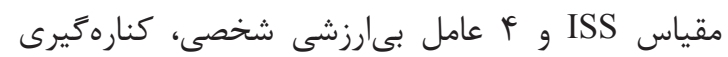

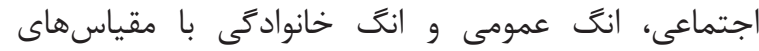

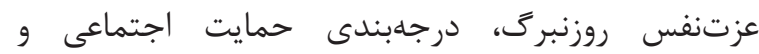

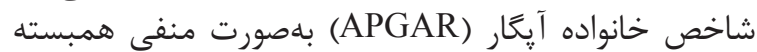

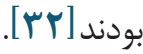

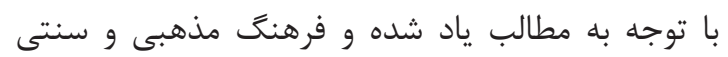

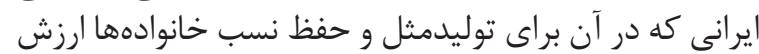

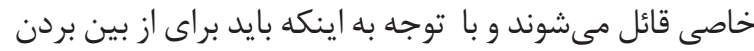

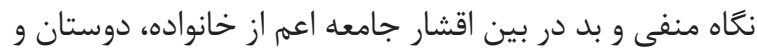

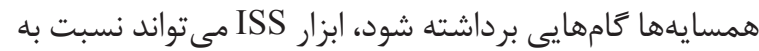

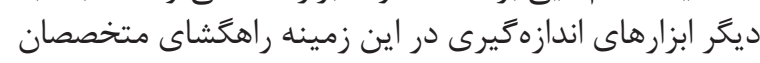

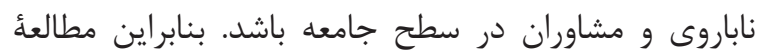

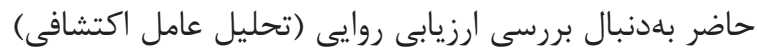

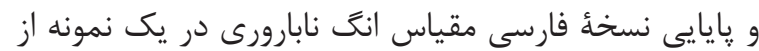

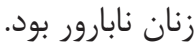

\section{روش كار}

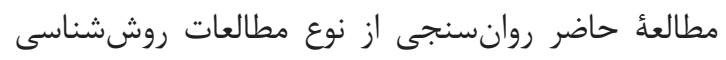

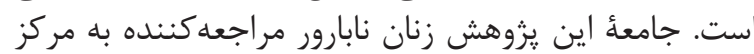

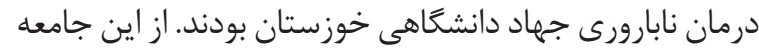

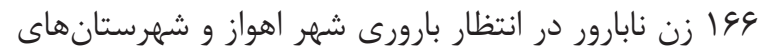

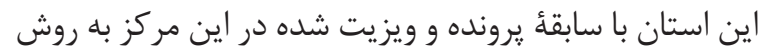

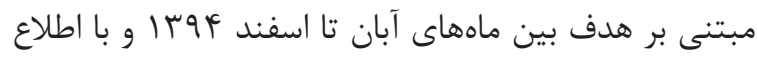

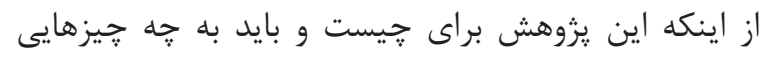

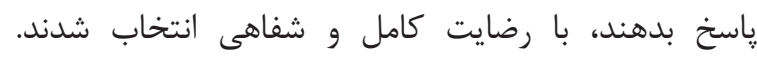

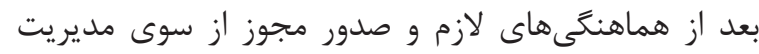

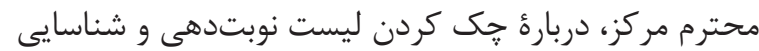

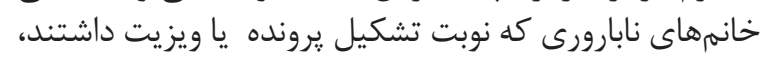

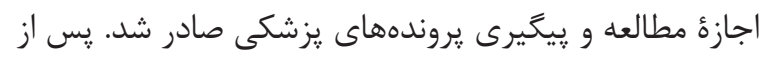

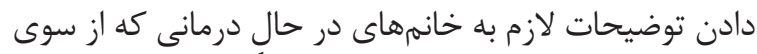

خود استيخماكرى هستند [11]. بر طبق نظر Goffman خاستگًاه انَ (استيخما) تفاوت

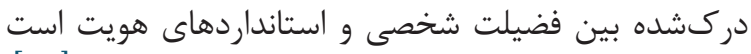

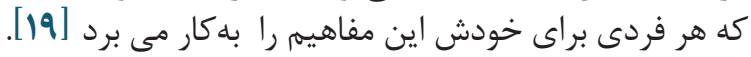

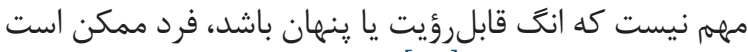

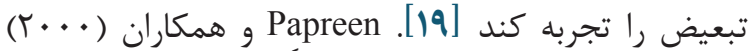

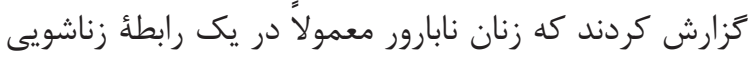

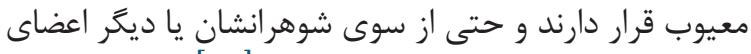

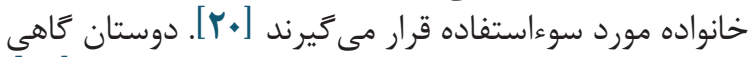

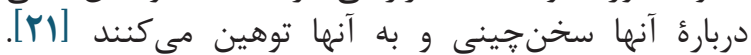

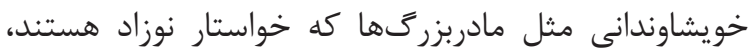

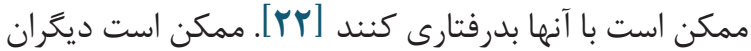

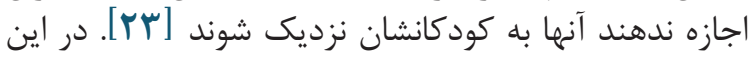

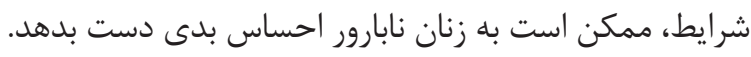

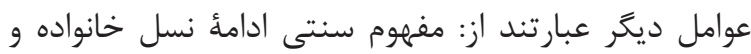

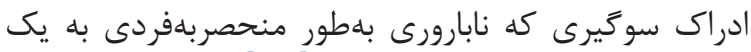

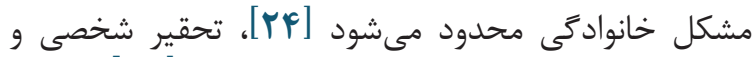

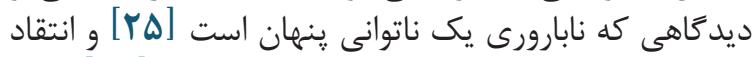

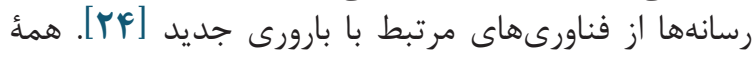
اينها مى توانند هزينأ انگ زنان مان نابارور باشند.

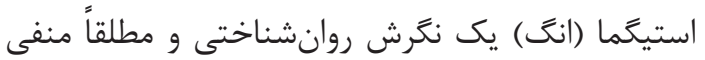

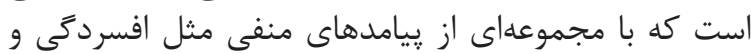

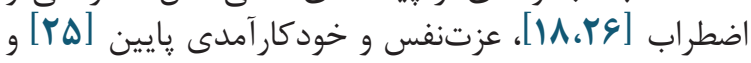

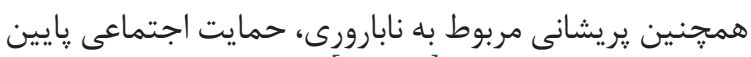

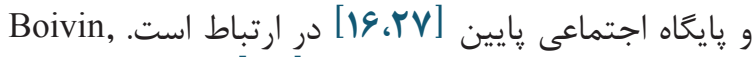
Stephen and,$[r \wedge]$ Bunting, Collins and Nygren

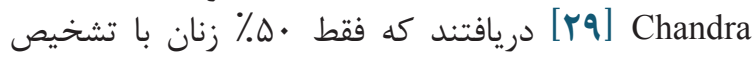

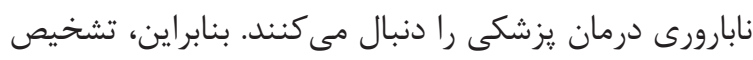

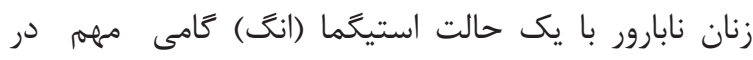

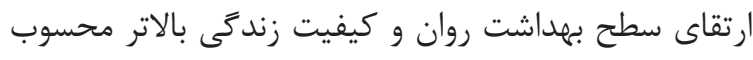

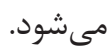

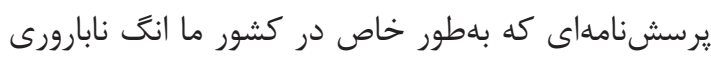

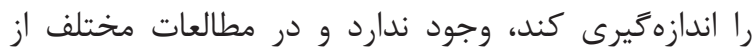
مقياسهاى انغ ادراكشده (Perceved Stigma Scale)

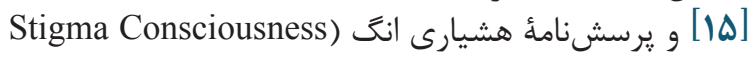

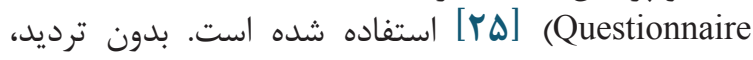

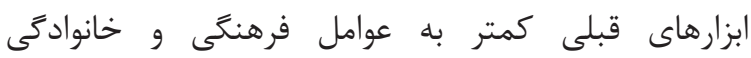

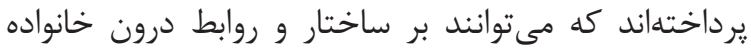

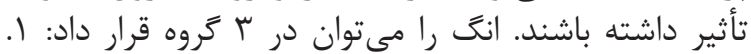

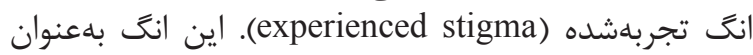

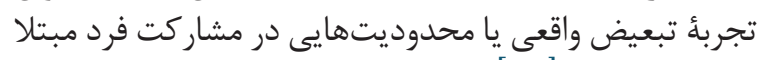

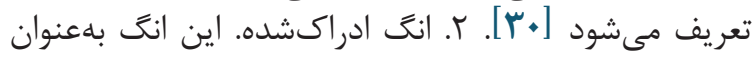

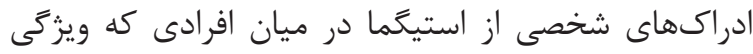

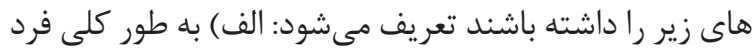

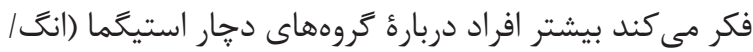

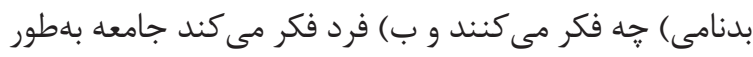

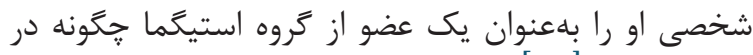

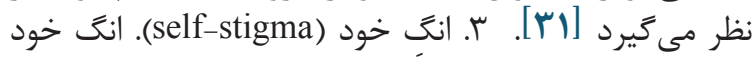


متغير باشد كه نمرءٔ بالا بيانكر ميزان بالاى باورها و انتظارات

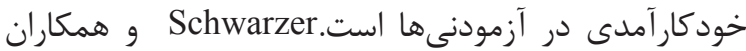

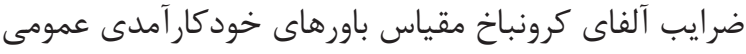

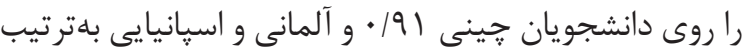

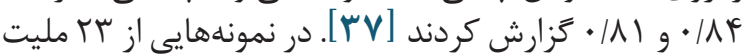

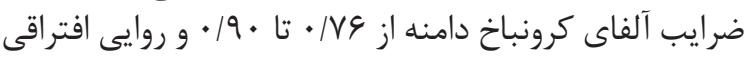

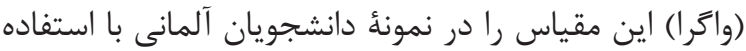

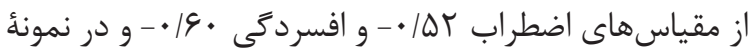

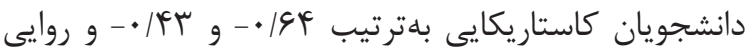

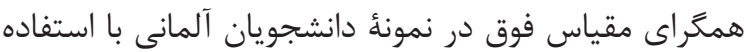

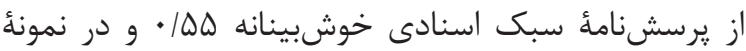

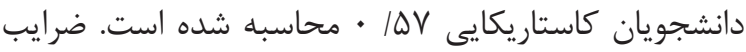

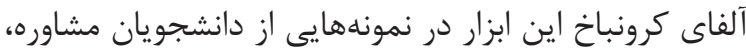

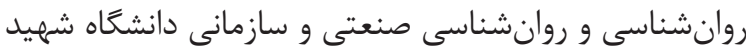

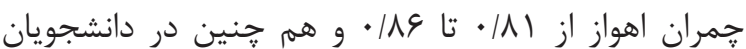

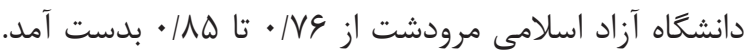

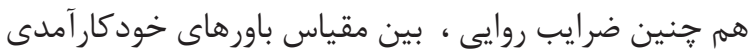

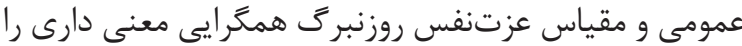

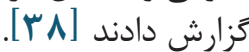

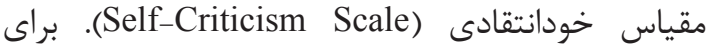
اندازمگيرى خود انتقادى از مقياس خود انتقادى، حمله به خود و قوت قلب (Y) Self-criticizing/attacking \& Selfreassuring Scale (FSCRS)) Gilbert

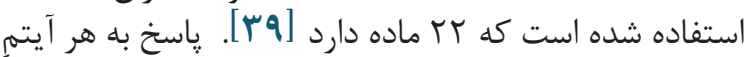

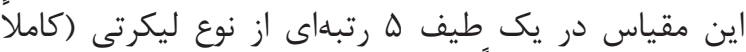

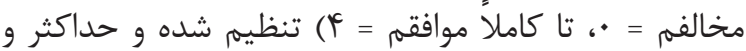

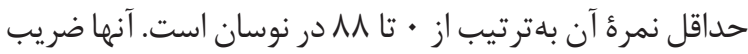

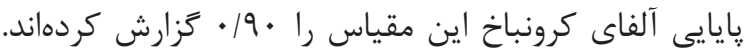
Rajabi و ورايب همسانى درونى (آلفاى كرونباخ)

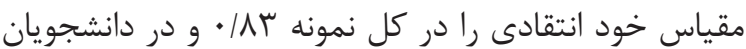

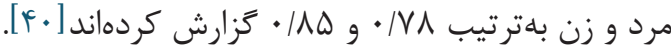

$$
\text { روش تجزيهوتحليل دادهها }
$$

تحليل دادها با استفاده از روشهاى زير انجام شد:

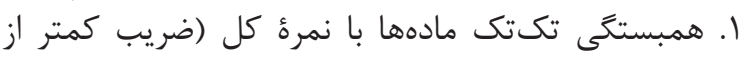

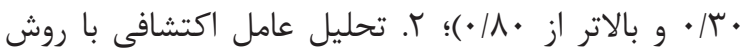

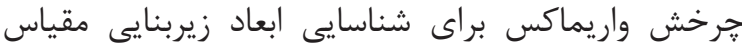

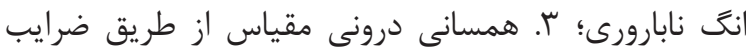
بايايى آلفاى كرونباخ (Cronbach a reliability) (برائ

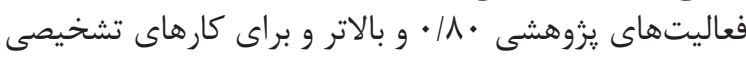

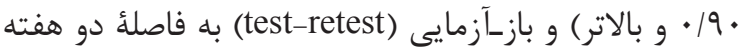

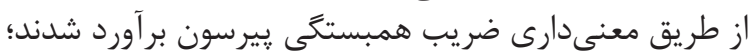

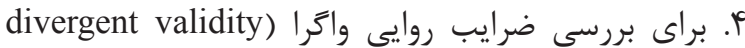

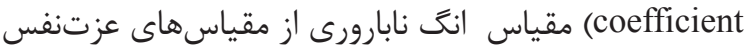

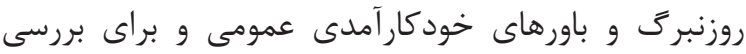

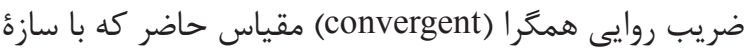

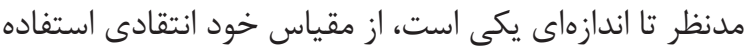

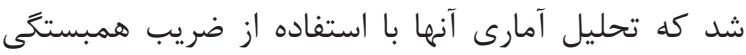

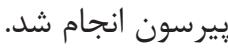

يزشكهاى معالج و كارشناسهاى مامايى مركز شناسايى

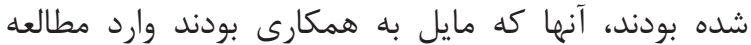

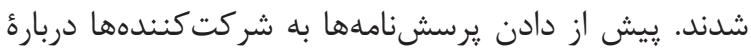

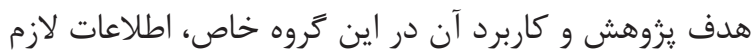

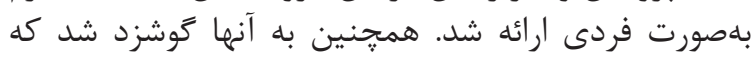

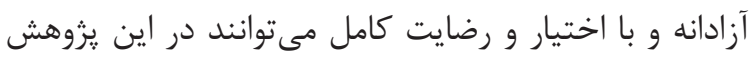

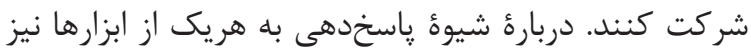

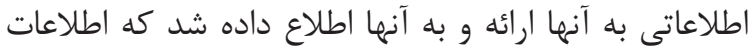

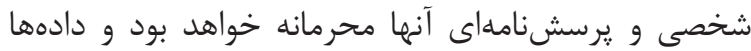

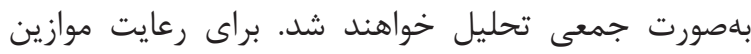

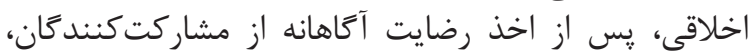

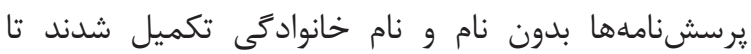
محرمانه بودن اطلاعات تأمين شود. نام خانوان

مقياس انغَ نابارورى (Infertility Stigma Scale). اين اين

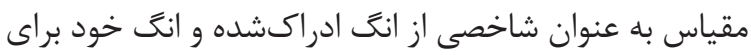

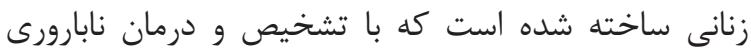

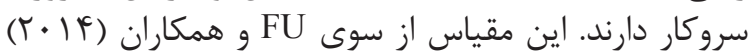

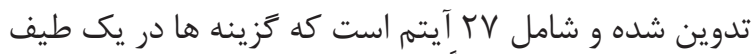

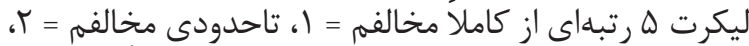

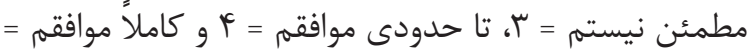

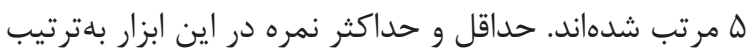

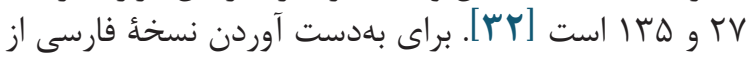
ترجمه ـ ترجماولارون (back translation) استفاده شد. مقياس عزتنفس روزنبرى (Sosenberg Self-esteem)

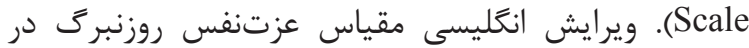

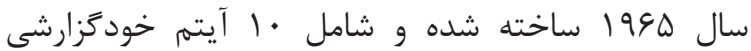

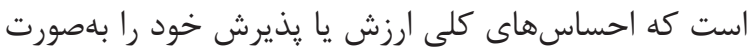

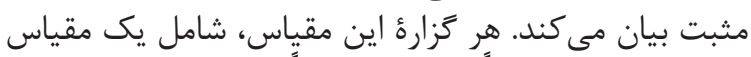

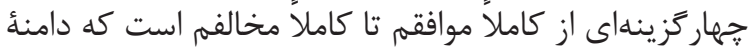

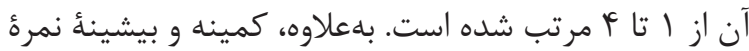

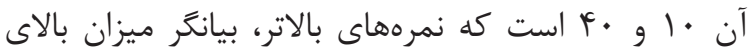

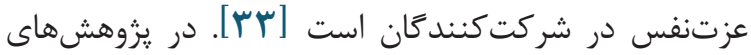
Rajabi, Rajabi and Bohlol، و همكار and Karju Kasmai

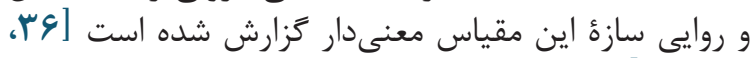

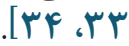

مقياس باورهاى خودكارآمدى عمومى (General Self-) efficacy Beliefs Scale

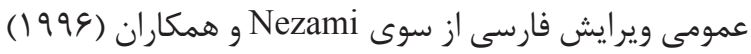

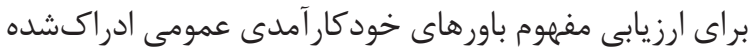

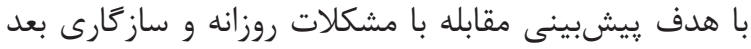

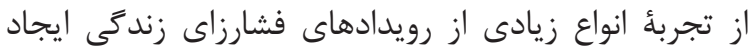

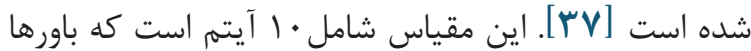

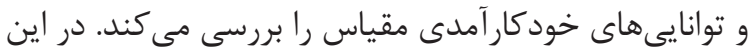

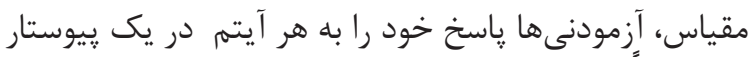

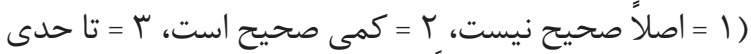

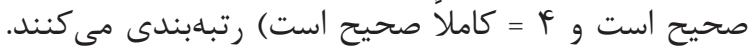

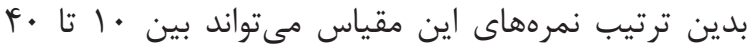


يافته ها

جدول ا. ويزَّى هاى جمعيتى گَروه نمونه

\begin{tabular}{|c|c|c|c|c|}
\hline حداكثر & حداقل & انحرافمعيار & ميانكين & متغير \\
\hline 48 & iv & $9 / 1 \mathrm{~V}$ & $r \cdot / r v$ & سن \\
\hline ra & 1 & $\Delta / \cdot T$ & $9 / N r$ & مدت نابارورى \\
\hline & درصد فراوانى & فراوانى & \multicolumn{2}{|c|}{ متغير } \\
\hline & $\% r v / r$ & $\Delta \cdot$ & فاميلى & \multirow{4}{*}{ ازدواج } \\
\hline & $\% 9 N / 9$ & 1.9 & غيرفاميلى & \\
\hline & $\% 1 \ldots$ & 109 & جمع & \\
\hline & $\% r / r$ & v & بدون مشخصه & \\
\hline & $\% 9 / 4$ & iv & ابتدايى & \multirow{9}{*}{ ميزان تحصيلات } \\
\hline & $\% 9 / r$ & 10 & سيكل & \\
\hline & $\% \Delta / \Delta$ & 9 & كمتر از دييلم & \\
\hline & $\% r \cdot 10$ & 99 & دييلم & \\
\hline & $\% 9 / V$ & 11 & فوق دييلم & \\
\hline & $\% r r / l$ & rq & كارشناسى & \\
\hline & $\% \Delta / \Delta$ & 9 & كارشناسى ارشد & \\
\hline & $\% 1 \ldots$ & 194 & جمع & \\
\hline & $\% 1 / \wedge$ & r & بدون مشخصه & \\
\hline & $\% \mathscr{F} / \Delta$ & 49 & درمان دارويى & \multirow{6}{*}{ درمان } \\
\hline & $\%$ \%/9 & ir & تست سونو & \\
\hline & $\% \pi r$ & rt & تلقيح داخلى رحمى اسيرم & \\
\hline & $\% r \cdot 19$ & rq & بارورى در آزمايشكاه & \\
\hline & $\% 1$. & 149 & جمع & \\
\hline & $\% 19 / \pi$ & tr & بدون مشخصه & \\
\hline & \%T/T & $\vee \cdot$ & ا سال & \multirow{5}{*}{ مدت درمان } \\
\hline & $\% T r / \Delta$ & rq & ا تا ب سال & \\
\hline & $\% \mathrm{~V} / \mathrm{\Lambda}$ & r & r تا ه سال & \\
\hline & $\% \Upsilon \varphi / \Delta$ & fq & $>\infty$ & \\
\hline & $\% 1$. & 199 & جمع & \\
\hline
\end{tabular}

جدول r. ميانگين، انحر افمعيار و ضرايب همبستغى بين آيتمها و نمرء كل مقياس انَى نابارورى

\begin{tabular}{|c|c|c|c|c|c|}
\hline $\mathbf{r}_{\mathrm{tt}}$ & ميانَين (انحرافمعيار) & كزينه ها & $\mathbf{r}_{\mathrm{tt}}$ & ميانگين (انحرافمعيار) & كز ينه ها \\
\hline $.19 Y^{*}$ & $(1 / / T) 1 / Q T$ & 10 & $\cdot 109^{* \prime}$ & $(1 / T I) 1 / A V$ & 1 \\
\hline$\cdot / V Y^{*}$ & $(1 / F T) T / \cdot r$ & 19 & $.199^{\circ}$ & (1/1.) & r \\
\hline$\cdot \mid \omega \phi^{*}$ & $(1 / r I) 1 / V F$ & IV & $\cdot 109^{\prime \prime}$ & $(1 / A \Lambda) 1 / \Delta F$ & r \\
\hline$\cdot / \mathrm{V}^{*}$ & $(1 / 4 \cdot) 1 / 94$ & 11 & $\cdot \mid q^{\mu^{*}}$ & $(1 / F \Delta) T / T V$ & r \\
\hline$\cdot / V \Delta^{*}$ & $(1 / f \Delta) r / \mu$ & 19 & $\cdot / V r^{*}$ & r/א (1/DI) & $\Delta$ \\
\hline $.199^{\circ}$ & $(1 / / F) 1 / q$. & $r$. & $\cdot|V| *$ & $(1 / \Delta F) \Gamma / \Delta \Delta$ & 4 \\
\hline$\cdot / V Y^{*}$ & $(1 / F I) T / I V$ & r) & $\cdot|V| *$ & $(1 / F T) Y / T r$ & v \\
\hline$\cdot \mid q \mathrm{~V}^{\circ}$ & $(1 / \uparrow \varphi) r / \cdot q$ & rt & $\cdot 109^{\circ}$ & Tr/ & $\wedge$ \\
\hline. $\mid 9 r^{*}$ & $(1 / \mathcal{e} V) r / / \varphi$ & זr & $\cdot|V| *$ & $(1 / 9 \Delta) T / V V$ & 9 \\
\hline$\cdot / \Delta \Lambda^{*}$ & $(1 / T r) 1 / V q$ & TF & $\cdot 10 \varphi^{*}$ & $(1 / 10) 1 / 9$. & 1. \\
\hline$\cdot / V \cdot *$ & $(1 / F \mid) T$ & $r \Delta$ & $\cdot / 4 \cdot *$ & $(1 / G \cdot) T / \mathcal{G} V$ & 11 \\
\hline$\cdot \mid F F^{\prime \prime}$ & $(1 / \pi \Delta) 1 / A r$ & rG & . kF" & $(1 / \Delta \Lambda) r / 9 \Delta$ & IT \\
\hline $.109 "$ & $(1 / T V) I / V r$ & TV & $\cdot \mid \Delta \mathrm{V}^{*}$ & $(1 / \Delta r) Y / \Lambda F$ & r \\
\hline \multicolumn{2}{|c|}{$(r \Psi / \& \varphi) \Delta \& / q \Psi$} & جمع & $\cdot 10 \Delta^{\prime \prime}$ & $(1 / \cdot r) 1 / \Delta 1$ & if \\
\hline & & $\mathrm{P} \leq$ & & & \\
\hline
\end{tabular}


واريماكس (varimax rotation) استفاده شد كه يك روش است

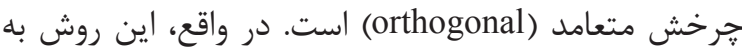

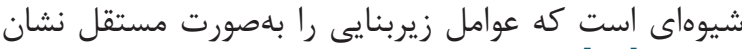

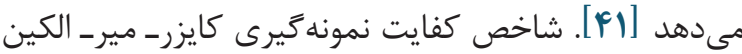
The Kaiser-Mayer-Olkin measure of sampling) Bartlett's Test) بآزمون كرويت بارتلت (adequacy

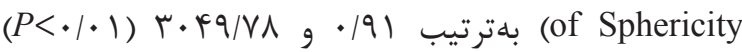
بهدست آمد و نشان مىدهد كه مفروضههاى آمارى نرمال

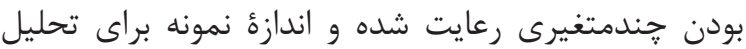

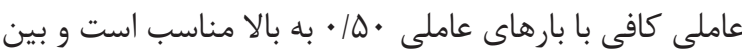

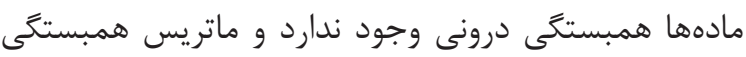

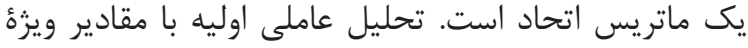

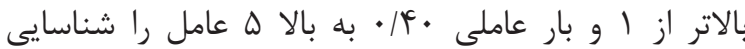

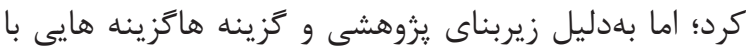

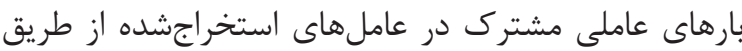

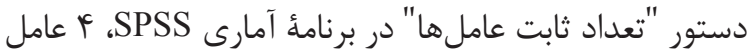

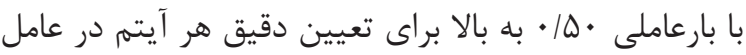

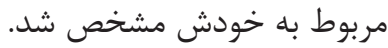

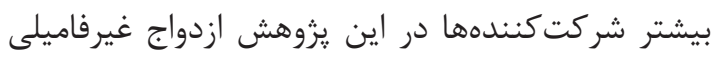

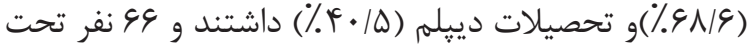

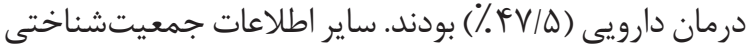
شركت كنندهها در جدول شمارها إن درج شده است.

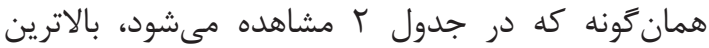

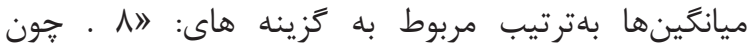

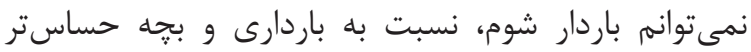

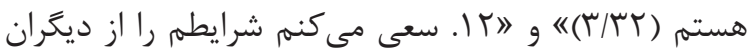

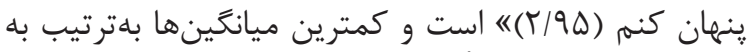

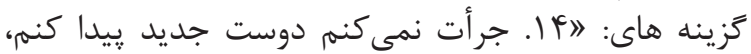

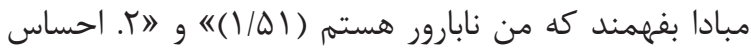

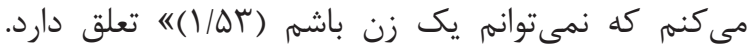

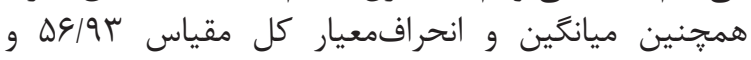

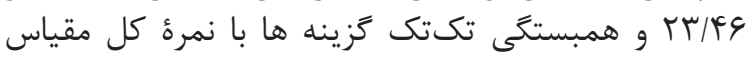

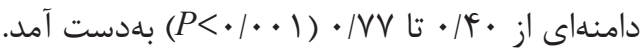

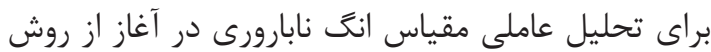
تحليل مؤلفههاى اصلى (principle component analysis)

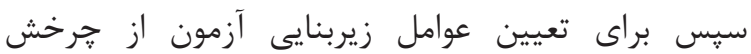

جدول ب. ماتريس عاملى گحرخ يافتهُ واريماكس مقياس انَ نابارورى با روش تحليل مؤلفههاى اصلى

\begin{tabular}{|c|c|c|c|c|c|c|c|c|c|}
\hline \multicolumn{10}{|c|}{ عاملها } \\
\hline p & $r$ & $r$ & 1 & كزينه ها & f & $r$ & $r$ & 1 & كزينه ها \\
\hline - & $\cdot / V V$ & - & - & 10 & - & - & - & $\cdot 19 V$ & 1 \\
\hline - & $\cdot 109$ & - & - & 19 & - & - & - & $\cdot 19 \mathrm{~V}$ & $r$ \\
\hline - & $\cdot \mid q V$ & - & - & IV & - & - & - & $\cdot|\Delta|^{F}$ & $r$ \\
\hline - & - &.$|9|$ & - & 11 & - & - & & $\cdot \mid \Delta F$ & $r$ \\
\hline - & - &. $\mid 94$ & - & 19 & - & - & $\cdot|\Delta|$ & $\cdot|\Delta|$ & $\Delta$ \\
\hline - & - & . & - & $r$. & - & - & - & $\cdot / \Delta \Delta$ & 9 \\
\hline - & - & $\cdot|V|$ & - & r) & - & - & - & $\cdot / \Delta \Delta$ & $v$ \\
\hline - & - & - & $\cdot / \mathrm{N}$ & rr & $\cdot / \Delta V$ & - & - & $\cdot \mid \Delta 9$ & $\wedge$ \\
\hline - & - & - & $\cdot / V \Delta$ & r & $\cdot / \omega$. & - & - & & 9 \\
\hline - & - & . $/ \Delta r$ & $\cdot / \Delta \Delta$ & TF & - & - & - & $\cdot|\Delta|$ & 1. \\
\hline - & - & .190 & $\cdot \mid \Delta Q$ & ra & $\cdot / V F$ & - & - & - & 11 \\
\hline - & - & $\cdot|Q|$ & - & re & $\cdot / \mathrm{V}^{2}$ & - & - & - & $\pi$ \\
\hline \multirow[t]{4}{*}{-} & - & $\cdot 19$. & - & tr & - & - & $\cdot / D T$ & - & זו \\
\hline & & & & & - & $\cdot / \mathrm{V}$ & - & - & if \\
\hline & & & & & $1 / 1 r$ & $1 / 9 \pi$ & $1 / 19$ & $|r / \mu|$ & مقادير ويثه \\
\hline & & & & & $F / d V$ & 91.4 & $9 \mid 9 T$ & $|9 \Delta / 9|$ & برصد واريانس \\
\hline
\end{tabular}

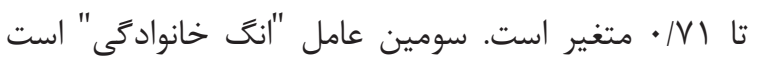

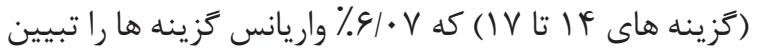

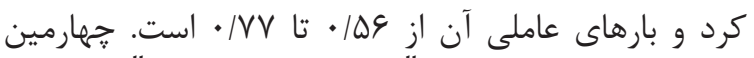

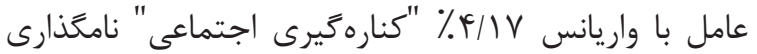

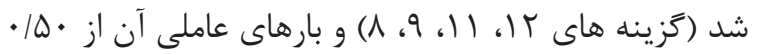

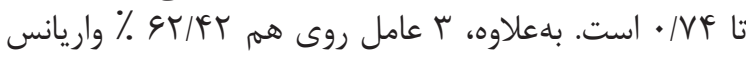

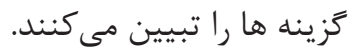

همانطور كه در جدول r ملاحظه مىشود، عامل اول

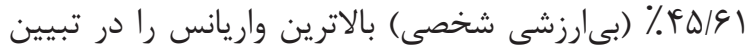

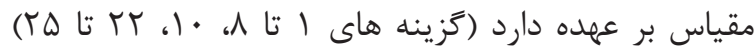

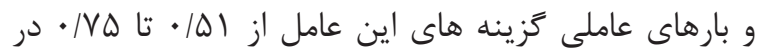

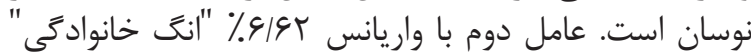

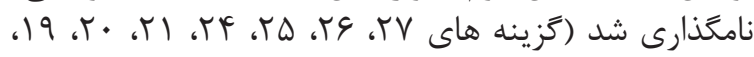

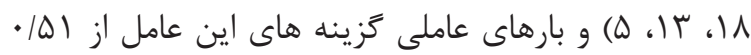




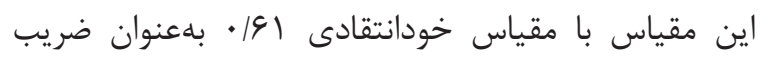

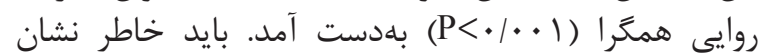

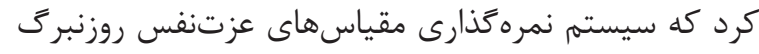

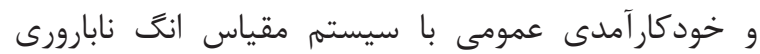

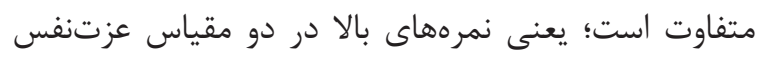

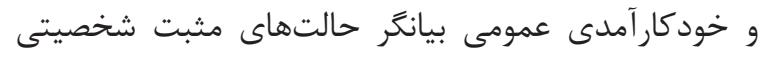

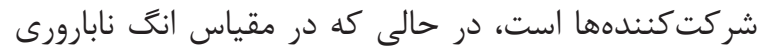

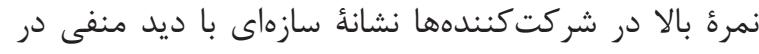

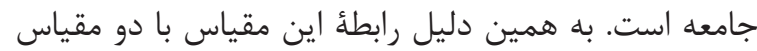
مذكور، مثبت شده است.

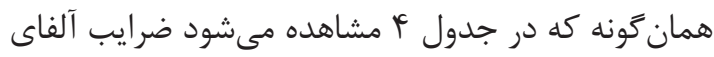

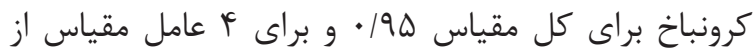

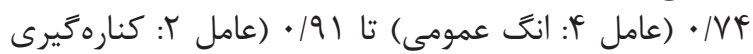

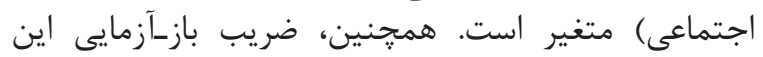

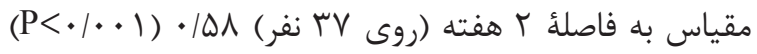
بلهدست آمد.

همان طور كه در جدول ه ملاحظه مىشود، همبستَّى

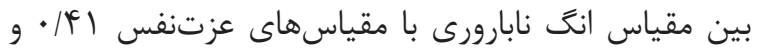

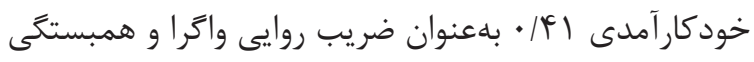

جدول F. ضرايب يايايى آلفاى كرونباخ مقياس انَ نابارورى

\begin{tabular}{|c|c|c|c|c|}
\hline انحراف استاندارد & ميانكَين & آلفاى كرنباخ & تعداد ماده & عامل \\
\hline $9 / 4 V$ & $19 / 94$ & $\cdot 19$ & 1. & بىارزشى خود \\
\hline $9 / \pi$ & IN/GT & .191 & 9 & كنارهگيرى اجتماعى \\
\hline r/qr & $9 / V 9$ & $\cdot \mid \Lambda \Delta$ & q & انََ عمومى \\
\hline$F / V Q$ & $11 / 4 \pi$ & $\cdot / N F$ & r & انعَ خانوادكى \\
\hline tr/TE & $\Delta \xi / 9 T$ & .190 & rV & كل مقياس \\
\hline
\end{tabular}

جدول ه. ضرايب روايى سازهُ واترا و همعَرا مقياس انَ نابارورى (ISS)

\begin{tabular}{|c|c|c|c|}
\hline روايى همكرا & \multicolumn{2}{|c|}{ روايى واترا } & \multirow{2}{*}{ مقياس } \\
\hline خودانتقادى & خودكار آمدى عمومى & عزتنفس & \\
\hline .191 & $\cdot|4|$ & $\cdot|f|$ & انگ نابارورى \\
\hline
\end{tabular}

و باورهاى خودكار آمدى عمومى، شواهدى از روايى واكرا را را

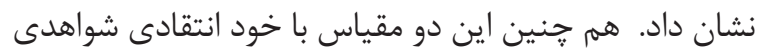

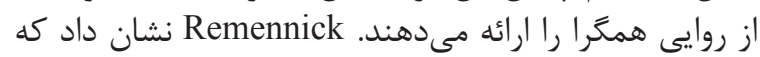

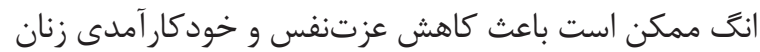

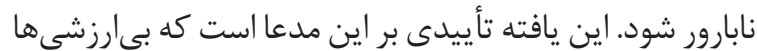

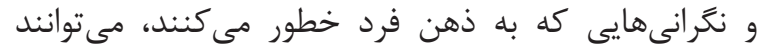

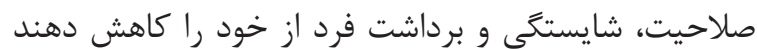

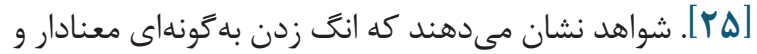

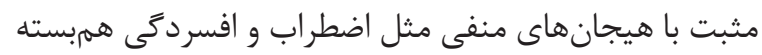

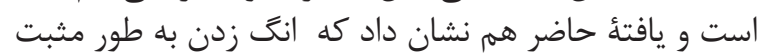

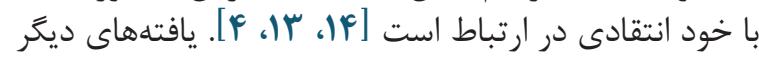

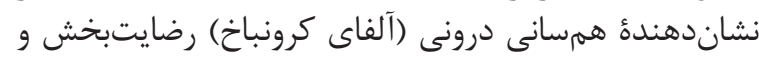

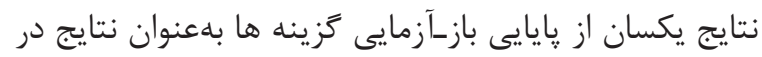

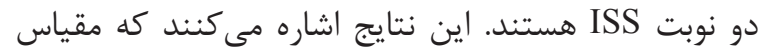

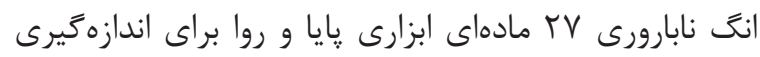

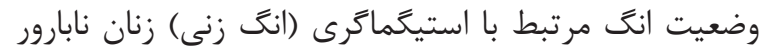

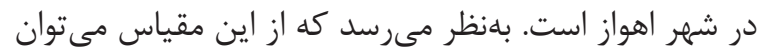

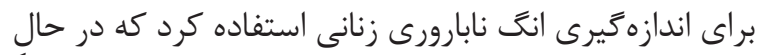

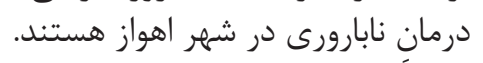

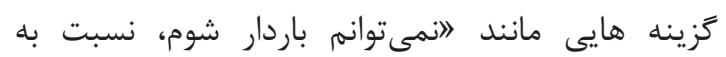

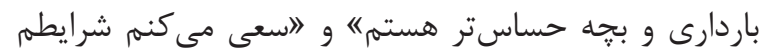

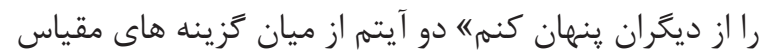

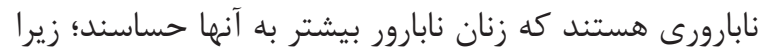

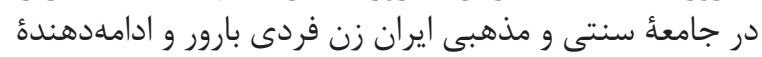

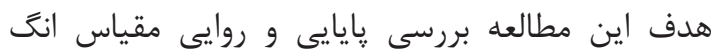

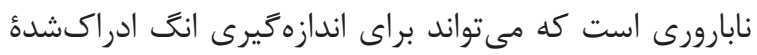

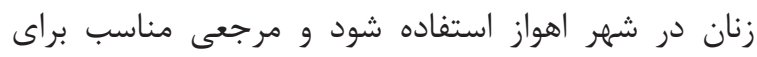

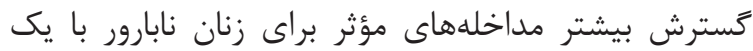

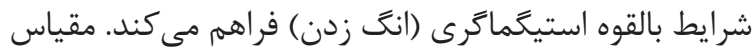

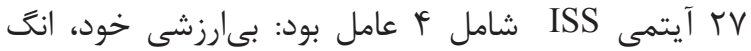

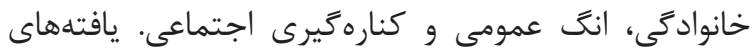

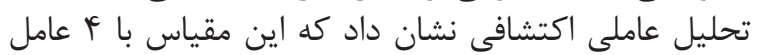

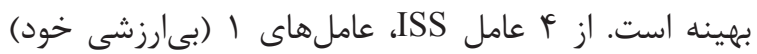

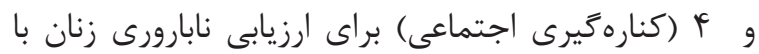

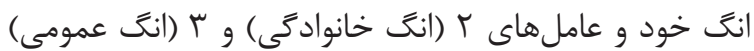

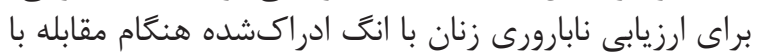

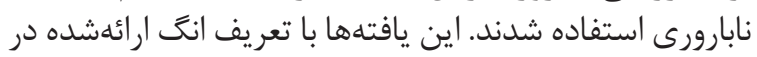

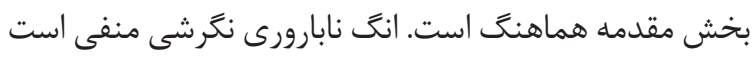

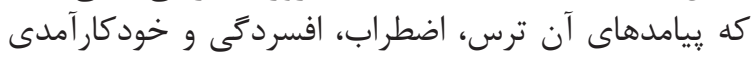

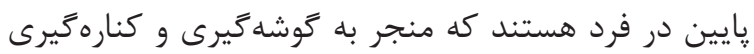

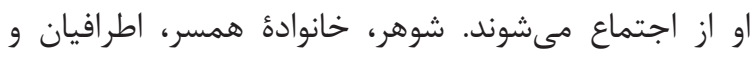

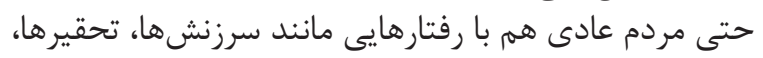

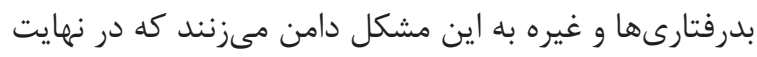

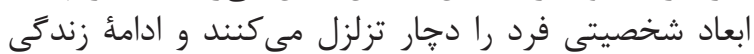

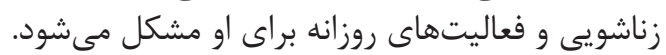

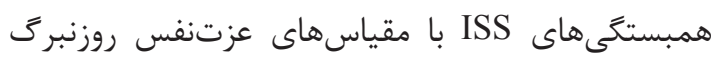


وضعيت 》انابارورى ينهان" ناميده ميىشود، را تفكيك كند إندان

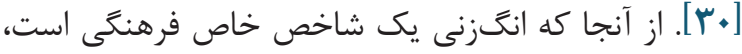

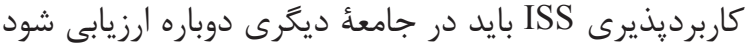

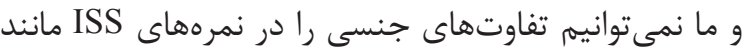

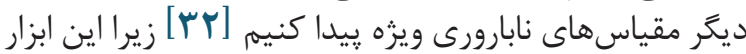

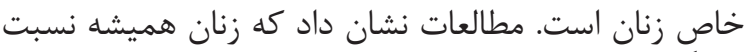

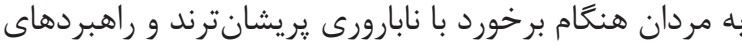

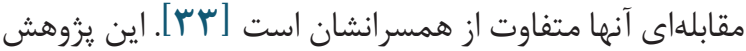

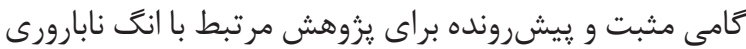

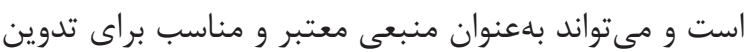

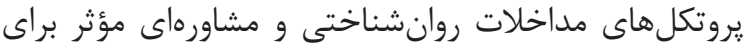

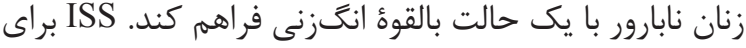

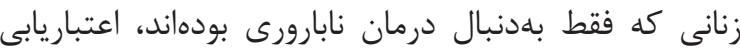
شده است و نه براى همهُ زنان نابارور.

\section{سياسگزَارى}

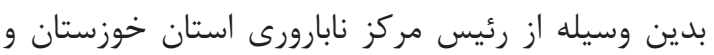

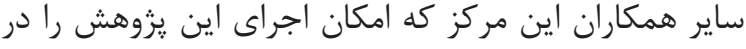

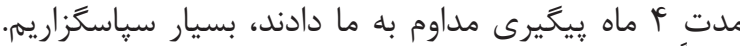

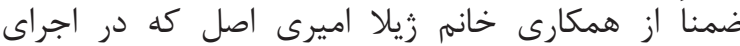

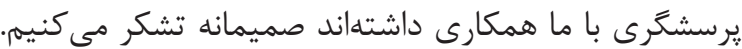

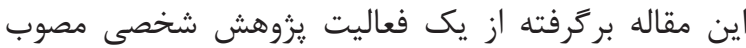

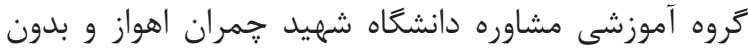
حمايت مالى از سوى دانشگاه و سازمان خاصى است داهُ

\section{تضاد در منافع}

بين نويسند كان هيج گَونه تضاد در منافع انتشار اين مقاله

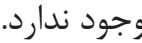

زندكَ بهحساب مى آيد و ديد و نكاه جامعه هم در اين راستا

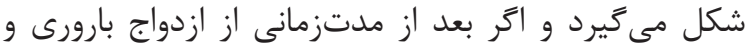

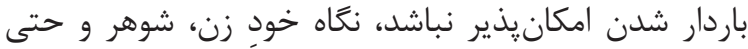

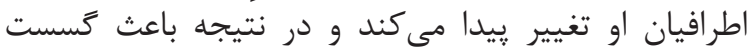

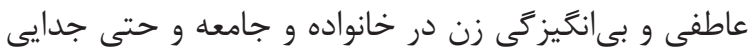

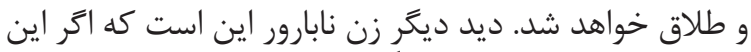

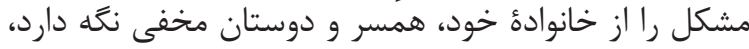

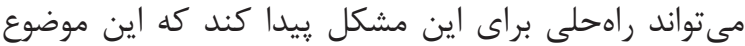

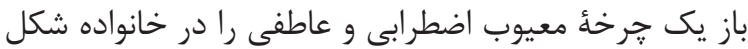

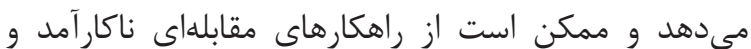
بحرانساز استفاده كنند.

محدوديت اين مطالعه فقط منحصر به نمونه زنان نابارورى

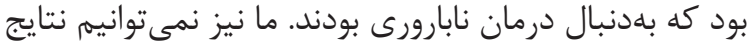

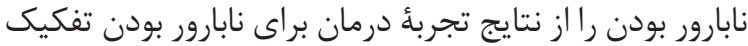

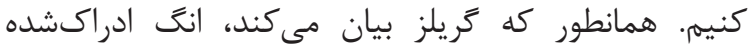
با رفتارهاى جستجوى سلامتى در زنانى با موانع نابارورى

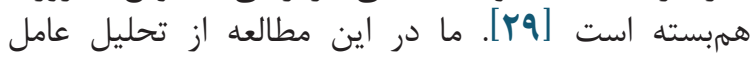

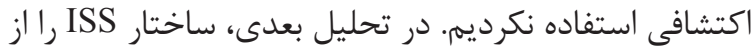

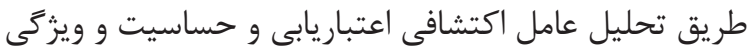

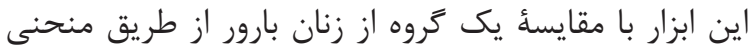
ويزگى خصيصه بررسى خواهيم كرد.

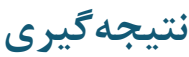

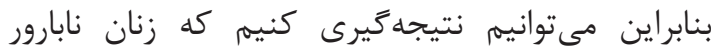

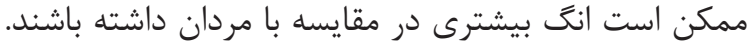
مقياس ISS ما قادر نيست تجارب زئن زنانى كه امكان باردار

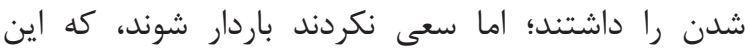

\section{References}

1. Practice Committee of the American Society for Reproductive Medicine. Definitions of infertility and recurrent pregnancy loss: A committee opinion. Fertil Steril. 2013; 99: 63.

2. Mascarenhas MN, Flaxman SR, Boerma T, Vanderpoel S,Mathers CD, Stevens GA. Trends in primary and secondary infertility prevalence since 1990: a systematic analysis of demographic and reproductive health surveys. Lancet. 2013;381:S90. https://doi.org/10.1016/S01406736(13)61344-6

3. Dirkund Moghadam A, Del Pisheh A, Sayehmiri K. The prevalence of infertility in Iran, A systematic review. Iran J Obstet Gynecol Infertil. 2013;16(81):1-7.

4. Pasch LA, Christensen A. Couples facing fertility problems. In: Schmaling KB, Sher TG, eds. The psychology of couples and illness. Washington, DC: American Psychological Association. 2000:241-67. https://doi.org/10.1037/10360-009

5. Stanton AL, Danoff-Burg S. Selected issues in

women's reproductive health: psychological perspectives. In: Stanton AL, Gallant SJ, Eds. The psychology of women's health: Progress and challenges in research and application. Washington, DC: American Psychological Association. 1995:261-305. https://doi.org/10.1037/10178$\underline{007}$

6. Leiblum SR. The impact of infertility on sexual and marital satisfaction. Annu Rev Sex Res. 1994;4:99-120.

7. Dunkel-Schetter C, Lobel M. Psychological reactions to infertility. In: Stanton AL, Dunkel-Schetter C, eds. Infertility: Psychological perspectives from stress and coping research. New York: Plenum, 1991:29-60. 5. Leiblum SR, ed. Infertility: Psychological issues and counseling strategies. New York: Wiley; 1997.

8. Pasch LA, Dunkel-Schetter C, Christensen A. Differences between husbands' and wives' approach to infertility affect marital communication and adjust. Fertil Steril. 2002;1241-47. https://

$$
\text { مجلئ علمى دانشكده پرستارى و مامايى همدان }
$$




\section{doi.org/10.1016/S0015-0282(02)03097-2}

9. Ferreira M, Antunes L, Duarte J, Chaves C. Influence of infertility and fertility adjustment on marital satisfaction. Procedia Soc Behav Sci. 2015;171:96-103. https://doi.org/10.1016/j.sbspro.2015.01.09

10. Martins MV, Costa P, Peterson BD, Costa ME, Schmidt L. Marital stability and repartnering: Infertility-related stress trajectories of unsuccessful fertility treatment. Fertil Steril. 2002;102(6):1716-22. https://doi.org/10.1016/j. fertnstert.2014.09.007 PMid:25439808

11. Stotland NL. Psychiatric issues related to infertility, reproductive technologies and abortion. Prim Care. 2002;29(1):13-26. https://doi.org/10.1016/ S0095-4543(03)00071-X

12. Boivin J, Appleton TC, Baetens P, Baron J, Bitzer J, Corrigan E. Guidelines for counselling in infertility: Outline version. Hum Reprod. 2001;16(6):1301-4.https://doi.org/10.1093/humrep/16.6.1301 PMid:11387309

13. Brkovich AM, Fisher WA. Psychological distress and infertility: Forty years of research. J Psychsom Obstet Gynaecol. 1998;19(4):218-28. https://doi.org/10.3109/01674829809025700

14. Hasanin IMA, Abd-El-Raheem T, Shain AY. Primary infertility and health-related quality of life in Upper Egypt. Int J Gynaecol Obstet. 2010;110:118-21. https://doi.org/10.1016/j. ijgo.2010.02.015 PMid:20546746

15. Lemmens GM, Vervaeke M, Enzlin P, Bakelants E, Vanderschueren D, D’Hooghe T, et al. Coping with infertility: a body-mind group intervention program for infertility couples. Hum Reprod. 2004;19(8):1917-23. https://doi.org/10.1093/ humrep/deh323 PMid:15155608

16. Donkor E, Sandall J. The impact of perceived stigma and mediating social factors on infertility-related stress among women seeking infertility treatment in Southern Ghana. Soc Sci Med. 2007;65:1683-94. https://doi.org/10.1016/j. socscimed.2007.06.003 PMid:17673344

17. Fido A, Zahid MA. Coping with infertility among Kuwaiti women: cultural perspectives. Int J Soc Psych. 2004;50(4):294-300. https://doi.org/10.1177/0020764004050334 PMid:15648743

18. Li H, Yan CL, Zhu SJ, Lei J. Humiliation Feeling of Infertile Women and Its Relevant Factors. Chin Gene Practice. 2010;13:1627-9.

19. Goffman E. Stigma: notes on the management of spoiled identity [J]. New York: Prentice-Hall; 1963.

20. Papreen N, Sharma A, Sabin K, Begum L, Ahsan SK, Baqui AH. Living with infertility: Experiences among urban slum populations in Bangladesh. Reprod Health Matters. 2000;8:33-44. https://

$$
\text { rا ا. ارزيابى پايايى و روايى نسخهُ فارسى مقياس ... }
$$

doi.org/10.1016/S0968-8080(00)90004-1

21. Fledderjohann JJ. Zero is not good for me: implications of infertility in Ghana. Hum Reprod. 2012;27:1383-90. https://doi.org/10.1093/humrep/des035 PMid:22357772

22. Tabong PT, Adongo PB. Infertility and childlessness: a qualitative study of the experiences of infertile couples in Northern Ghana. BMC pregnancy childbirth. 2013;13:72.https://doi. org/10.1186/1471-2393-13-72 PMid:23517021 PMCid:PMC3610195

23. Tabong PT, Adongo PB. Understanding the social meaning of infertility and childbearing: a qualitative study of the perception of childbearing and childlessness in Northern Ghana. PLoS One. 2013;8:e54429. https://doi.org/10.1371/ journal.pone.0054429 PMid:23342158 PMCid:PMC3546987

24. Matsubayashi H, Hosaka T, Izumi S, Suzuki T, Kondo A, Makno T. Increased depression and anxiety in infertile Japanese women resulting from lack of husband's support and feelings of stress. Gen Hosp Psychiatry. 2004;26:398-404. https:// doi.org/10.1016/j.genhosppsych.2004.05.002 PMid:15474640

25. Remennick L. Childless in the Land of Imperative Motherhood: Stigma and coping among infertile Israeli women. Sex Roles. 2000;43:82141. https://doi.org/10.1023/A:1011084821700

26. Davis M, Ventura J L, Wieners M, Covington SN, Vanderhoof VH, Ryan ME, et al. The psychosocial transition associated with spontaneous 46, XX primary ovarian insufficiency: illness uncertainty, stigma, goal flexibility, and purpose in life as factors in emotional health. Fertil Steril. 2010;93:2321-9. https://doi.org/10.1016/j.fertnstert.2008.12.122 PMid:19243752 PMCid:PMC3013503

27. Slade P, Neill CO, Simpson AJ, Lashen H. The relationship between perceived stigma, disclosure patterns, support and distress in new attendees at an infertility clinic. Hum Reprod. 2007;22:230917. $\quad$ https://doi.org/10.1093/humrep/dem115 PMid: 17580298

28. Boivin J, Bunting L, Collins JA, Nygren KG. International estimates of infertility prevalence and treatment-seeking potential need and demand for infertility medical care. Hum Reprod. 2007;22:1506-12. https://doi.org/10.1093/humrep/dem046 PMid:17376819

29. Stephen E, Chandra A. Declining estimates of infertility in the United States. Fertil Steril. 2006;86:516-23. https://doi.org/10.1016/j.fertnstert.2006.02.129 PMid:16952500

30. Van Brakel WH, Anderson AM, Mutatkar RK, Bakirtzief Z, Nicholls PG, Raju MS, et al. The Participation scale: measuring a key concept in 
public health. Disabil Rehabil. 2006;28:193-03. https://doi.org/10.1080/09638280500192785 PMid:16467054

31. LeBel T. Perceptions of and responses to stigma. Soc Compass. 2008;2:409-32. https://doi. org/10.1111/j.1751-9020.2007.00081.x

32. FU B, Qin N, Cheng L, Tang G, Cao Y, Yan C, Zhu S, Lei J. Development and validation of an Infertility Stigma Scale for Chinese women. J Psychosom Res. 2015;79(1):69-75. https://doi. org/10.1016/j.jpsychores.2014.11.014

33. Rajabi GH, Bohlol N. The reliability and validity of Rosenberg Self-Esteem Scale in freshman students of Shahid Chamran University of Ahvaz. J Edu Psychol Res. 2008;33(8):33-48.

34. Greenberger E, Chen C, Dmitrieva J, Farruggia SP. Item-wording and dimensionality of the Rosenberg self-Esteen Scale: do they matter? Pers Indiv Differ. 2003;35(6):1241-54. https:// doi.org/10.1016/S0191-8869(02)00331-8

35. Pullmann H, Allik J. The Rosenberg self-Esteem Scale: Its dimensionality، stability and personality correlates in Estonian. Pers Indiv Differ. 2000;28:701-15. https://doi.org/10.1016/S01918869(99)00132-4

36. Rajabi Gh, Karju Kasmai S. A Study of structure two-factor model the Persian version of the Rosenberg Self-esteem Scale. J Psychol Mod method. 2011;2(6):33-43.

37. Schwarzer R, Bassler J, Kwiatek P, Schroder K, Zhang JX. The assessment of optimistic self-beliefs: Comparison of the German, Spanish, and Chinese Versions of the General Self-efficacy Scale. App Psychol Int Rev. 1997;46(1):6988. $\quad$ https://doi.org/10.1111/j.1464-0597.1997. tb01096.x

38. Rajabi Gh. The Validating and the Comparison of the General Self-efficacy beliefs Scale (GSE10 ) in Shahid Chamran University Students and Islamic Azad University of Marvdast. Mod Educ Thought. 2006;2(1):111-22.

39. Gilbert P, Clarke M, Hempel s, Miles J, Irons C. Criticizing and reassuring oneself: an exploration of forms, styles and reasons in female students. Br J Clin Psychol. 2004;43(1):31-50. https://doi.org/10.1348/014466504772812959 PMid:15005905

40. Rajabi Gh, Abbasi Gh. The relationship of self-criticism, social anxiety and fear of failure with shyness in college students. J Clin Couns Res. 2011;1(2):171-82.

41. Byrne BM. Structure equation modeling with AMOS: Basic concepts, applications, and programming. 3nd ed. New Jersey: Lawrence Erlbaum Associates, Mahwah; 2001; p 81

$$
\begin{aligned}
& \text { 19. نكران هستم كه وقتى افراد به نابارورىام يى مىبرند، }
\end{aligned}
$$

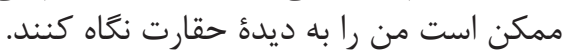

$$
\begin{aligned}
& \text { IV } \\
& \text { ممكن است به من بخنداسند }
\end{aligned}
$$

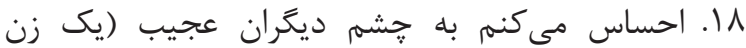

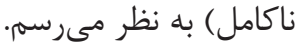

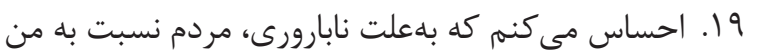

$$
\begin{aligned}
& \text { قضاوت خوبى ندارند. }
\end{aligned}
$$

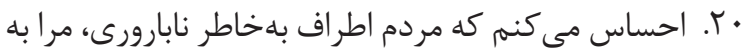

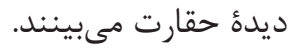

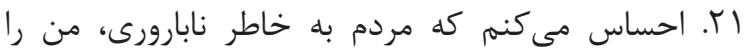

$$
\begin{aligned}
& \text { متفاوت مىبينند. } \\
& \text { rr. نابارورى زندگى من من را نابود كرده است. }
\end{aligned}
$$

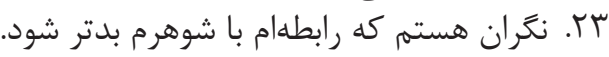

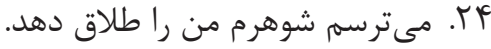

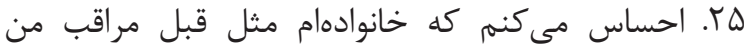

$$
\begin{aligned}
& \text { نيستند. } \\
& \text { צr. خانوادهام بهخصوص مادرشوهرم، هميشه برايم مشكل }
\end{aligned}
$$

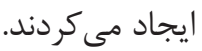

$$
\begin{aligned}
& \text { VV } \\
& \text { مجددم را تحتتأثير قرار دهد مدرد }
\end{aligned}
$$

$$
\begin{aligned}
& \text { ضميمه: َززينه هاى مقياس انَ نابارورى }
\end{aligned}
$$

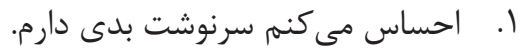

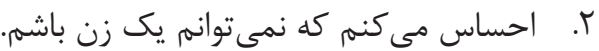

$$
\begin{aligned}
& \text { r. }
\end{aligned}
$$

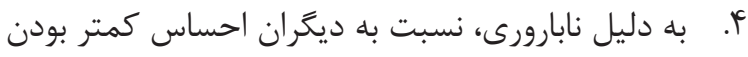

$$
\begin{aligned}
& \text { مى كنم. } \\
& \text { ه. از لمابارور بودن شرمنده هستم. }
\end{aligned}
$$

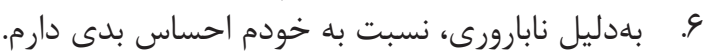

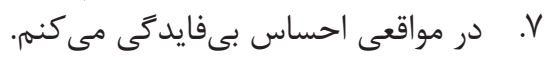

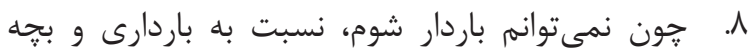

$$
\begin{aligned}
& \text { حساستر هستم. }
\end{aligned}
$$

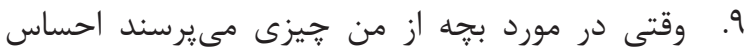

$$
\begin{aligned}
& \text { شرمنده بودن مى كنم. } \\
& \text { • ا. از نزديك شدن بهن افرادى كنه كه مشكل نابارورى ندارند } \\
& \text { دورى مى كنم. } \\
& \text { Iا ا. تمايلى به صحبت دمبت در مورد نابارورى ندارم. }
\end{aligned}
$$

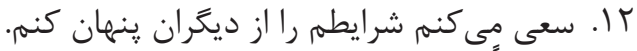

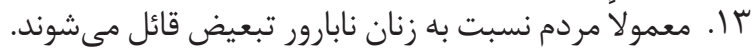

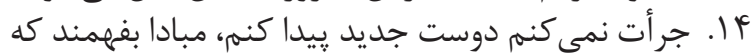

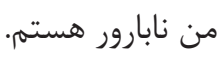

$$
\begin{aligned}
& \text { ها. نَخران هستم كه وقتى افراد به نابارورىام يبى مىبرند، از } \\
& \text { من دور شوند. }
\end{aligned}
$$

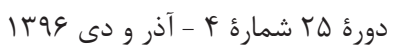

